\title{
Estimating water availability across the Upper Salween and Mekong river basins
}

\author{
SUXIA LIU' ${ }^{1}$, WENHAO DING ${ }^{1,3}$, CHANGMING LIU1 ${ }^{1}$, LIFANG LIU ${ }^{1,3}$, \\ SAGAR BAJRACHARYA ${ }^{2}$, ARUN SHRESTHA ${ }^{2} \&$ NEERA SHRESTHA PRADHAN ${ }^{2}$ \\ 1 Key Laboratory of Water Cycle and Related Land Surface Processes, Institute of Geographic Sciences and Natural \\ Resources Research, Beijing, 100101, China \\ liusx@igsnrr.ac.cn \\ 2 ICIMOD, Nepal \\ 3 University of Chinese Academy of Sciences
}

\begin{abstract}
According to Liu et al. (2014), borrowing, substituting and generating (BSG) are the main methods people used to acquire the discharge at ungauged stations. Two of the substitution (modelling and disaggregation) methods in combination with the borrowing idea are compared for simulating discharge for the Upper Salween and Mekong River Basin (USMRB). It is seen that with a simple borrowing/ disaggregating method, the Nash-Sutcliffe Efficiency (NSE) can reach 0.82 . The similarity in the seasonal variation pattern is a more important requirement to identify if the two stations are to be considered as having hydrological similarity. From the experience obtained for the USMRB, an upstream station with shorter geographical distance may be more in hydrological similarity than a station in the far downstream. The NSE is quite low when borrowing occurs within the low altitude downstream region. The efficiency will be decreased when we borrow information from several stations which may be not in hydrological similarity.
\end{abstract}

Key words Upper Salween; Mekong River; PUB; disaggregating; HIMS Model

\section{INTRODUCTION}

The Upper Salween and Mekong river basins (USMRB) are rich in water resources. Water availability is important for regional planning and water resources management. As a very sensitive area to climate change, whether the water will be always available is a hot topic. To predict the future, one needs to know the history. Nowadays, there are a few discharge gauges in USMRB supplying historical information; however, there are not nearly enough to provide the water availability information along the rivers.

Hydrological prediction for data-scarce basins is very important to hydrology research. Limited by the natural conditions and/or changed by human activities, there are a lot of basins which have not yet set up gauging stations or do not yet have significant amounts of gauged data. For data-scarce basins, Liu et al. (2010, 2014) summarized a methodology for hydrological prediction, including the Borrow method (B), Substitute method (S) and Generation (G) method. Borrowing is obtaining hydrological information by transplanting measurements from a similar basin, extrapolating/interpolating the data from neighbouring catchments. Substituting is finding substitutes either from the ungauged basin or from donating area(s), and Generating is obtaining data via field or laboratory observations. Finding substitutes is classified further into S1, which is only within the ungauged basin by using fully process-based models without calibration; S2-1, which is from similar gauged basins by using established index/distribution; S2-2, which is from various gauged basins by using regression and/or process-based relationships between the climate/catchment features and hydrological signatures $(\mathrm{CCH})$; and $\mathrm{S} 3$, which uses the information beyond the $\mathrm{CCH}$ relationship.

In practice, borrowing the discharge at the nearest stations is the primary method people always use to acquire the discharge for an ungauged basin due to its simple features. The second simple method is the disaggregation procedure, which belongs to S2-1. According to the principle of hydrological similarity, the sub-basins belonging to one basin are always similar. The discharge for the gauged basin is first scaled by its contributing area. Then the streamflow for the ungauged basin can be predicted with this scaled streamflow by multiplying with the contributing area of the ungauged basin. This disaggregation technique is based on the assumption that the streamflow contribution from each sub-catchment to the total catchment yield is proportional to the ratio of its 
areas and its average slope (Schreider et al. 2002, Liu et al. 2014). The third popular method is to use hydrological models to simulate discharge based on input information (such as meteorology, land cover, soil, vegetation, etc.), which belongs to S2-1 or S2-2. As a fully physical hydrological model without calibration (S2-1) to a certain degree needs more input information, types of semiphysical process models (S2-2), which need less input information, are finding wide application.

Based on the conditions of USMRB, we will compare the above mentioned rational methods for estimating water availability, aiming to recommend a practical method for determining longterm water availability for USMRB. Some new techniques in the combination of these methods are explored.

\section{METHODOLOGY}

\subsection{Study area}

USMRB is located in southwest China (Fig. 1) where the Mekong River is located, $94^{\circ} \mathrm{E}-102^{\circ} \mathrm{E}$, $21^{\circ} \mathrm{N}-34^{\circ} \mathrm{N}$; it has a vast elevation difference north to south, and is narrow in the west-east direction. The basin area of the upper Mekong River is $167400 \mathrm{~km}^{2}$, with a river length of $2161 \mathrm{~km}$, an elevation difference of $4583 \mathrm{~m}$ and an average gradient of $2.12 \%$. In the basin, the difference of climate is obvious. Temperature and precipitation generally increase from north to south; the higher the altitude, the lower the air temperature and the less precipitation. The whole basin has the southwest monsoon climate, with two seasons of dry and wet. Generally, the wet season is from May to October, the dry season is from November to the next April; about $85 \%$ of rainfall is concentrated in the wet season. The multi-year average runoff flow out of China is about 76 billion $\mathrm{m}^{3}$.

The Salween River lies at $91^{\circ} 10^{\prime} \mathrm{E}-100^{\circ} 15^{\prime} \mathrm{E}, 23^{\circ} 5^{\prime} \mathrm{N}-32^{\circ} 48^{\prime} \mathrm{N}$ and is similar in shape to that of the Mekong River. The basin has an area of $137800 \mathrm{~km}^{2}$, with the full-length being $2013 \mathrm{~km}$; the elevation difference is $4840 \mathrm{~m}$ and the average gradient is $2.04 \%$. The annual average temperature is significantly different between the north and south, increasing progressively north

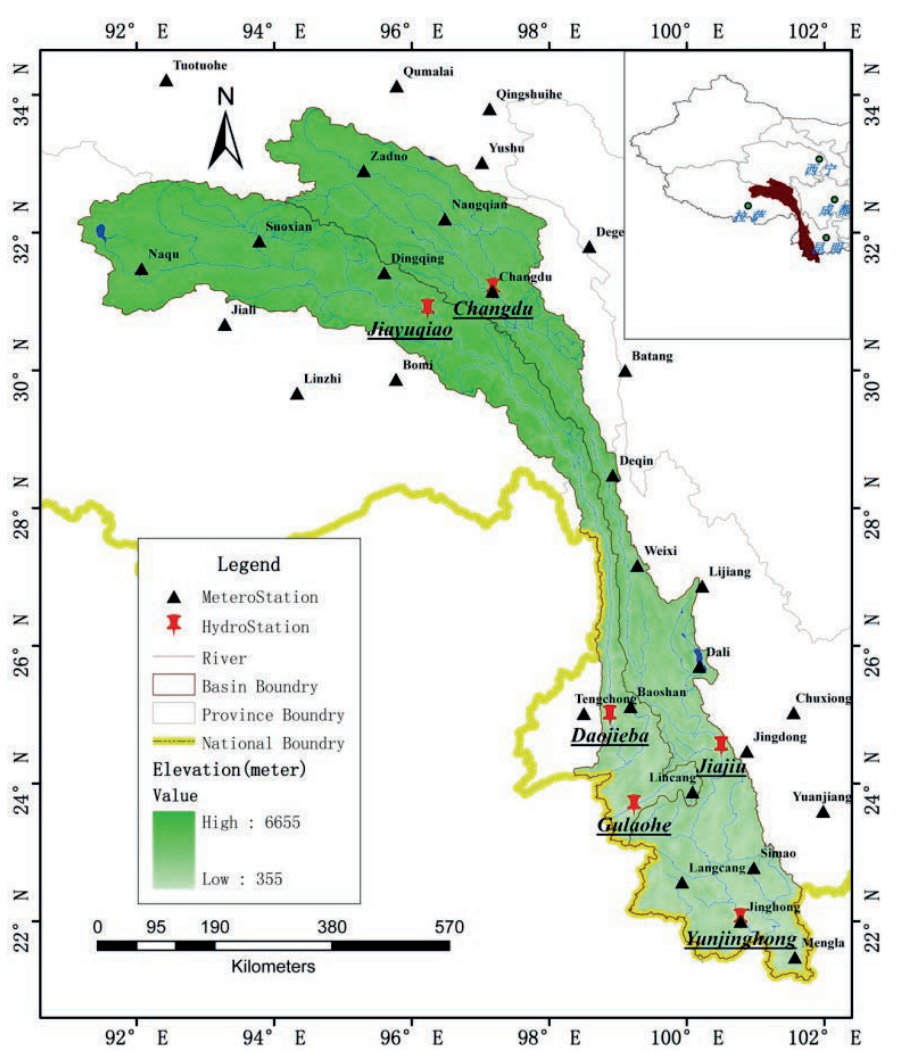

Fig. 1 Upper Salween and Mekong river basins and distribution of meteorological and hydrological stations. 
to south. The rainfall is influenced by geographical position, topography and climate conditions. The rainy season of Salween River is generally from May to October. The dry season is from November to the next April. The rainfall is very asymmetric over the basin. The multi-year average runoff flowing out of China is about 70.3 billion $\mathrm{m}^{3}$.

\subsection{Data}

Being an international river, there are limitations to accessing hydrological data in USMRB. We have collected some daily hydrological data for Changdu, Jiajiu, Yunjinghong, Jiayuqiao, Daojieba and Gulaohe hydrological Stations from hydrological yearbooks. The details of the hydrological data at these six stations is shown in Table 1.

Table 1 List of hydrological stations and their features.

\begin{tabular}{llllll}
\hline Basin & HydroStation & $\begin{array}{l}\text { Latitude } \\
{ }^{\circ} \mathrm{N}\end{array}$ & $\begin{array}{l}\text { Longitude } \\
{ }^{\circ} \mathrm{E}\end{array}$ & $\begin{array}{l}\text { Area } \\
\left(\mathrm{km}^{2}\right)\end{array}$ & Time series \\
\hline Mekong & Changdu (CD) & 31.18 & 97.18 & 48448 & $1991-1998,2000$ \\
River & Jiajiu (JJ) & 24.53 & 100.5 & 105660 & $1957-1959$ \\
& Yunjinghong (YJH) & 22.03 & 100.78 & 141380 & $1957-2007$ \\
Salween & Jiayuqiao(JYQ) & 30.88 & 96.23 & 69384 & $1991-2000$ \\
& Daojieba(DJB) & 24.98 & 98.88 & 110224 & $1960-1963,1965-1985$ \\
& Gulaohe(GLH) & 23.68 & 99.23 & 4185 & $1960-1963,1965-1985$ \\
\hline
\end{tabular}

Note: The actual full record of the data time series is far beyond of what we have collected. The present data are for the experiments for data scarce research.

Meteorological data including daily precipitation, daily maximum temperature and minimum temperature and daily average temperature, from 1 January 1957 to 31 December 2012 at thirty stations within and around USMRB were collected from the China Meteorological Administration (website: http://cdc.cma.gov.cn/home.do). Arithmetic and Thiessen polygon average methods were used to calculate the basin averages. The locations of the hydrological and meteorological stations in USMRB are shown in Fig. 1.

\subsection{Methods}

2.3.1 Disaggregation/borrowing method In USMRB, from the data we collected, there are three stations, i.e. CD, YJH and JYQ, which have a continuous shared data period from 1991 to 1998. Based on discharge at CD or YJH, we will get the discharge at YJH or CD by using the disaggregation method. The efficiency is compared by the Nash-Sutcliffe efficiency (NSE) and error of volume $(\mathrm{EV})$.

$$
\begin{aligned}
& N S E=1-\frac{\sum\left(Q_{o b s, i}-Q_{\text {sim }, i}\right)^{2}}{\sum\left(Q_{o b s, i}-\overline{Q_{o b s}}\right)^{2}} \\
& E V=\frac{\overline{Q_{s l m}}-\overline{Q_{o b s}}}{\overline{Q_{o b s}}} \times 100 \%
\end{aligned}
$$

The traditional disaggregation method only applies to the stations within a basin. Based on the idea of borrowing and disaggregation, we propose a technique to combine the borrowing and disaggregation methods together. That is, first borrowing the discharge at the gauged basin from another basin (for example $\mathrm{CD} / \mathrm{YJH}$ ), then using the disaggregation to get the discharge for the ungauged basin (for example JYQ). We will compare this innovative combination with the traditional disaggregation method at the daily, monthly and yearly scale.

2.3.2 Modelling/borrowing method As the example of S2-2, HIMS (Hydro-Informatic Modeling System) hydrologic model, developed by academician Liu Changming and his team (Liu et al. 2008, Zhou et al. 2014), was used for estimating the discharge for the ungauged basin. HIMS model integrates many current mature hydrological calculation methods with wide applications in 
the Yellow River, the Haihe River, Heihe River, Australian Murray Darling Basin, and American basins in California (Liu et al. 2010, Wu et al. 2012, Liu et al. 2013). The parameters of the HIMS model include the unsaturated soil layer water holding capacity or soil water storage capacity of $\mathrm{W}_{\mathrm{sm}}$, runoff coefficients $\mathrm{R}$ and $\mathrm{r}$, subsurface flow coefficient $\mathrm{La}$, coefficient of groundwater recharge $\mathrm{R}_{c}$, the actual evapotranspiration coefficient $\mathrm{e}$, baseflow coefficient $\mathrm{K}_{\mathrm{b}}$, and the coefficients of the Muskingum routing method, $\mathrm{C}_{1}$ and $\mathrm{C}_{2}$. The range of HIMS model parameters is shown in Table 2.

Table 2 The range of HIMS model parameters.

\begin{tabular}{llllllllll}
\hline Value & $\mathrm{W}_{\mathrm{sm}}$ & $\mathrm{R}$ & $\mathrm{r}$ & $\mathrm{La}$ & $\mathrm{R}_{\mathrm{c}}$ & $\mathrm{e}$ & $\mathrm{K}_{\mathrm{b}}$ & $\mathrm{C}_{1}$ & $\mathrm{C}_{2}$ \\
\hline Minimum & 50 & 0.1 & 0.1 & 0.1 & 0.01 & 0.01 & 0.01 & 0.05 & 0.05 \\
Maximum & 1500 & 5 & 0.99 & 1 & 1 & 10 & 0.7 & 0.9 & 0.9 \\
\hline
\end{tabular}

The parameters are calibrated using observed discharges at gauge stations with a particle swarm optimization algorithm. Then HIMS model can be used to predict discharge for ungauged stations.

In this paper we will compare three techniques for borrowing the parameters: (1) borrowing the parameters from a station within the same basin; (2) borrowing the parameters from stations located at the same altitude; (3) borrowing the parameters from all gauged stations in the study region.

\section{RESULTS}

\subsection{The results by using disaggregation/borrowing method}

By respectively assuming $\mathrm{CD}, \mathrm{YJH}$ and JYQ as the ungauged basin, by using the disaggregation/ borrowing method we can obtain the discharge at the corresponding ungauged basin based on the discharge at the gauged station. The efficiency is compared as shown in Table 3.

Table 3 The Nash-Sutcliffe efficiency coefficient (NSE) of discharge for CD, YJH and JYQ obtained by using the disaggregation method based on the discharge at one of CD, YJH and JYQ at daily, monthly and yearly scale. The last three columns are for EV, the values of which are the same at three scales.

\begin{tabular}{|c|c|c|c|c|c|c|c|c|c|c|c|c|}
\hline \multirow[t]{2}{*}{ Based } & \multicolumn{3}{|c|}{ NES_Daily } & \multicolumn{3}{|c|}{ NES_Monthly } & \multicolumn{3}{|c|}{ NES_Yearly } & \multicolumn{3}{|l|}{ EV } \\
\hline & $\mathrm{CD}$ & YJH & JYQ & $\mathrm{CD}$ & YJH & JYQ & CD & YJH & JYQ & $\mathrm{CD}$ & YJH & JYQ \\
\hline CD & -- & 0.51 & 0.82 & -- & 0.69 & 0.83 & -- & -2 & -0.4 & -- & -0.27 & -0.2 \\
\hline YJH & 0.25 & -- & 0.59 & 0.52 & -- & 0.77 & -2.43 & -- & 0.22 & 0.37 & -- & 0.11 \\
\hline JYQ & 0.66 & 0.5 & -- & 0.67 & 0.71 & -- & -0.76 & 0.16 & -- & 0.25 & -0.1 & -- \\
\hline
\end{tabular}

The overall impression from Table 3 is that borrowing/disaggregating information can improve the NSE to 0.82 at YJH to borrow the information from CD at daily scale. It is obvious that in USMRB if the station is in the upstream (like CD), it is better to borrow the information from the nearest station (JYQ), although it belongs to another basin, than to use the disaggregation method to borrow the discharge from downstream within the same basin (YJH).

Similarly, for JYQ, the NSE for borrowing the information from the near station at CD is higher than the NSE for borrowing the information from the further station at YJH. For the station downstream, YJH, there is no obvious difference between the NSE when borrowing information from CD and the NSE when borrowing information from JYQ.

The above phenomena can be well explained by the different features of the seasonal variation pattern for Salween and Mekong river basins, as shown in Fig. 2. It is found that although CD and $\mathrm{YJH}$ are from same basin, their seasonal patterns are not similar. Instead the seasonal pattern of CD follows the seasonal pattern of JYQ.

We can conclude that in order to reach a highly efficient borrowing/disaggregating, the two stations should have better hydrological similarity. The similarity in seasonal variation pattern is a more important requirement to identify whether the two stations are in hydrological similarity. If 


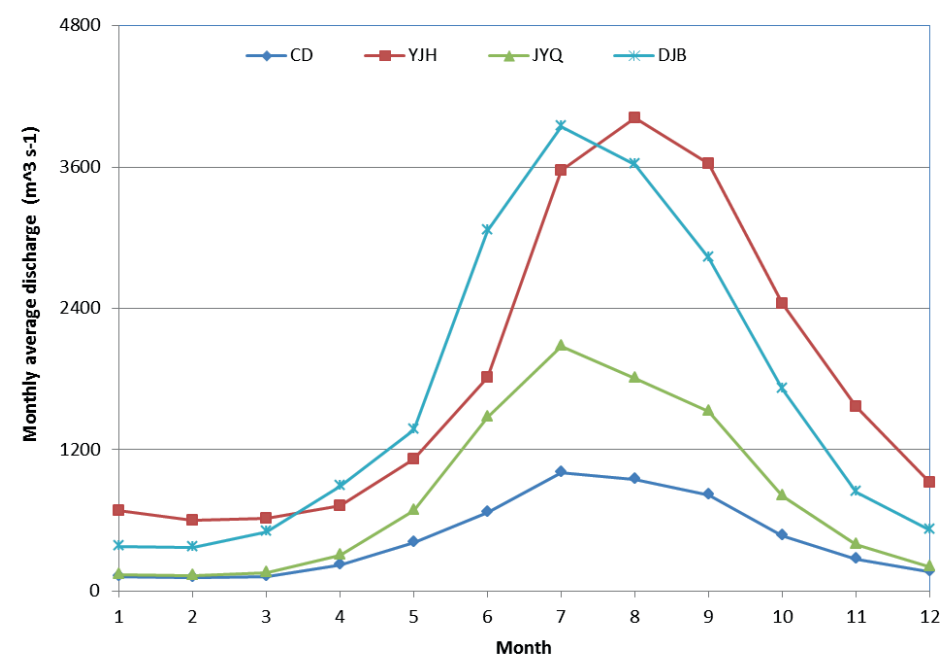

Fig. 2 The seasonal variation at four stations.

the seasonal variation pattern at the gauged station to be borrowed from is not similar to that of the ungauged basin, then location in the same basin is the important factor to consider.

For ungauged basins, it is not possible to get the information of seasonal variation pattern in advance. From the experience we obtained from USMRB, upstream stations with shorter geographical distance may be more in hydrological similarity than stations in the far downstream.

\subsection{The results by using the modelling/borrowing method}

The efficiency by using the optimized parameters at each station is shown in Table 4 . We can see that through optimization, for any period of data, for any station, the NSE can all reach values higher than 0.75 , and the error of volume can be within or near $-10 \%$.

Table 4 The NSE and error of volume at the four hydrological stations by using optimized parameters at daily, monthly and yearly scale. The values of EV are the same at all three time scales.

\begin{tabular}{lllll}
\hline Station & EV & NSE-daily & NSE-monthly & NSE-yearly \\
\hline CD & -0.09 & 0.82 & 0.88 & 0.67 \\
YJH & -0.05 & 0.83 & 0.9 & 0.57 \\
JYQ & -0.12 & 0.83 & 0.88 & 0.43 \\
DJB & -0.06 & 0.85 & 0.92 & 0.49 \\
\hline
\end{tabular}

By assuming that each of the four hydrological stations in turn is an ungauged basin, to borrow the parameters from the station within the same basin, from the station located at the same altitude and from the average of all the assumed gauged station respectively, the NSE and EV in each case is shown in Table 5. Similar to the disaggregating/borrowing method, the NSE when the borrowing occurs between $\mathrm{CD}$ and YJH is lower than the NSE when borrowing occurs between DJB and JYQ. This is because that CD and YJH do not have a similar seasonal variation pattern, while DJB and JYQ are in similar seasonal variation pattern, as shown in Fig. 2.

There is a question people may always ask: if we have more than one gauged stations to be able to borrow information from, is it better to utilize all of the available information? From the last three columns in Table 5 we can see that the efficiency will be decreased with such kind of borrowing from all others; the reason is still that the seasonal variation is not similar.

The above finding is true not only at daily scale but also at monthly scale (Table 6). Similar to the disaggregating/borrowing method, comparing all the time scales, the efficiency at monthly scale is highest, with the maximum efficiency reaching 0.83 when DJB borrows the information from JYQ. The efficiency is lowest at yearly scale. 
Table 5 The NSE and EV at the four hydrological stations by borrowing the parameters from the station within the same basin, from the station located in the same altitude and from the average of all the gauged station, at daily scale.

\begin{tabular}{|c|c|c|c|c|c|c|c|c|c|}
\hline \multirow[t]{2}{*}{ Station } & \multicolumn{3}{|c|}{ From the same basin } & \multicolumn{3}{|c|}{ From the Same altitude } & \multicolumn{3}{|c|}{ From all others } \\
\hline & $\mathrm{NSE}$ & $\mathrm{EV}$ & From & NSE & $\mathrm{EV}$ & From & NSE & EV & From \\
\hline $\mathrm{CD}$ & 0.64 & -0.35 & YJH & 0.71 & 0.00 & JYQ & 0.6 & -0.43 & YJH+JYQ+DJB \\
\hline YJH & 0.58 & 0.29 & $\mathrm{CD}$ & -0.58 & 0.63 & DJB & 0.45 & 0.26 & $\mathrm{CD}+\mathrm{JYQ}+\mathrm{DJB}$ \\
\hline JYQ & 0.75 & 0.05 & DJB & 0.69 & -0.19 & $\mathrm{CD}$ & 0.42 & -0.48 & $\mathrm{CD}+\mathrm{YJH}+\mathrm{DJB}$ \\
\hline DJB & 0.78 & -0.24 & JYQ & 0.3 & -0.5 & YJH & 0.32 & -0.52 & $\mathrm{CD}+\mathrm{YJH}+\mathrm{JYQ}$ \\
\hline
\end{tabular}

Table 6 The same as Table 5 but at monthly and yearly scale.

\begin{tabular}{|c|c|c|c|c|c|c|c|c|c|}
\hline \multirow[t]{2}{*}{ Station } & \multicolumn{3}{|c|}{ From the same basin } & \multicolumn{3}{|c|}{ From the same altitude } & \multicolumn{3}{|c|}{ From all others } \\
\hline & $\mathrm{NSE}_{\mathrm{m}}$ & $\mathrm{NSE}_{\mathrm{y}}$ & From & $\mathrm{NSE}_{\mathrm{m}}$ & $\mathrm{NSE}_{\mathrm{y}}$ & From & $\mathrm{NSE}_{\mathrm{m}}$ & $\mathrm{NSE}_{\mathrm{y}}$ & From \\
\hline CD & 0.67 & -2.03 & YJH & 0.77 & 0.78 & JYQ & 0.62 & -3.59 & YJH+JYQ+DJB \\
\hline YJH & 0.65 & -4.05 & $\mathrm{CD}$ & -0.74 & -15.37 & DJB & 0.46 & -1.93 & $\mathrm{CD}+\mathrm{JYQ}+\mathrm{DJB}$ \\
\hline JYQ & 0.81 & 0.09 & DJB & 0.77 & -0.24 & $\mathrm{CD}$ & 0.43 & -6.07 & $\mathrm{CD}+\mathrm{YJH}+\mathrm{DJB}$ \\
\hline DJB & 0.83 & -4.93 & JYQ & 0.28 & -23.68 & YJH & 0.31 & -25.86 & $\mathrm{CD}+\mathrm{YJH}+\mathrm{JYQ}$ \\
\hline
\end{tabular}

\section{SUGGESTIONS FOR ESTIMATING THE WATER AVAILABILITY ACROSS USMRB}

Although there are few hydrological stations in USMRB, the basins are not fully gauged. If we need to know the discharge at any cross-sections of the rivers, we have to methods such as researched in this paper.

For the USMRB, if we divide the region into four zones, to acquire the discharge at crosssections falling within these four zones, suggestions can be made based on the above analysis as shown in Table 7.

Table 7 Suggestions for acquiring the discharge for ungauged station in USMRB.

\begin{tabular}{|c|c|c|c|c|c|c|c|c|c|c|c|c|}
\hline \multirow[t]{2}{*}{ Choice } & \multicolumn{3}{|c|}{ Zone A (CD) } & \multicolumn{3}{|c|}{ Zone B(YJH) } & \multicolumn{3}{|c|}{ Zone C (JYQ) } & \multicolumn{3}{|c|}{ Zone D (DJB) } \\
\hline & a. & b. & c. & a. & b. & c. & a. & b. & c. & a. & b. & c. \\
\hline First & $\mathrm{D} / \mathrm{B}$ & JYQ & 0.71 & $\mathrm{M} / \mathrm{B}$ & $\mathrm{CD}$ & 0.58 & $\mathrm{D} / \mathrm{B}$ & $\mathrm{CD}$ & 0.82 & $\mathrm{M} / \mathrm{B}$ & JYQ & 0.78 \\
\hline Second & $\mathrm{M} / \mathrm{B}$ & JYQ & 0.66 & $\mathrm{D} / \mathrm{B}$ & $\mathrm{CD}$ & 0.51 & $\mathrm{M} / \mathrm{B}$ & DJB & 0.75 & - & - & - \\
\hline
\end{tabular}

Note: Column a. is the method recommended; column b. is the station to borrow the information from; column $\mathrm{c}$. is the NSE to be reached possibly at daily scale. D/B represents disaggregation/borrowing, M/B represents modelling/borrowing. The blank for the second choice in Zone D can be filled in the future work when the data for DJB is available for D/B.

\section{CONCLUSIONS}

Based on the BSG framework of the methodology for hydrological prediction for ungauged basins proposed by Liu et al. (2014), possible methods for estimating water availability cross USMRB are researched.

To reach a high efficiency by using both the borrowing/disaggregating and borrowing/ modelling method, with the Nash-Sutcliffe Efficiency (NSE), say, 0.82, the two stations should have good hydrological similarity. However, hydrological similarity does not simply refer to location in the same basin. The similarity in seasonal variation pattern is a more important requirement to identify if the two stations have hydrological similarity. From the experience obtained from USMRB, upstream stations with shorter geographical distance may be more in hydrological similarity than the station in the far downstream. NSE is quite low when borrowing occurs within the low altitude downstream region. The efficiency will be decreased when we borrow information from several stations which may be not in hydrological similarity.

Comparing different time scales, the efficiency at monthly scale is highest. The efficiency is lowest at yearly scale. The above methods are not suitable to acquire yearly runoff for an ungauged basin. 
Acknowledgements This paper is financially supported by the 973 project (2012CB957802) and ICIMOD HICAP project.

\section{REFERENCES}

Liu, C., et al. (2010) Based on the multi-scale integrated hydrological process simulation of HIMS. Journal of Beijing Normal University (Natural Science) 46(3), 268-273.

Liu, C., et al. (2012) Estimate the runoff in scarce information area based on HIMS Model. China 2012 Academic Conference on Hydrology, 525-530.

Liu, C., et al. (2013) Ascertain the flood peak runoff in Tibet scarce data area. South-to-North Water Transfers and Water Science \& Technology 11(1), 1-6.

Liu, L., et al. (2013) HIMS model parameters' uncertainty and its influencing factors. Progress in Geography 32(4), 532-537.

Liu, S., et al. (2014) On a PUB methodology from Chinese lessons. Hydrological Sciences Journal doi:10.1080/02626667. 2014.899702 .

Schreider, S.Y., et al. (2002) Prediction of monthly discharge in ungauged catchments under agricultural land use in the Upper Ping basin, northern Thailand. Mathematics and Computers in Simulation 59 (2002), 19-33.

Wu, M., Wang, Z. and Dang, S. (2012) Based on HIMS model simulate and analyze the runoff in the mountainous of upstream of Heihe. Resources Science 34(10), 1913-1921.

Zhou, C., et al. (2014) From the experiment of hydrology to the hydrologic system simulation. Acta Geographica Sinica 69(5), $588-594$. 